Article

\title{
Optical Properties of Bismuth Tellurite Based Glass
}

\section{Hooi Ming Oo, Halimah Mohamed-Kamari * and Wan Mohd Daud Wan-Yusoff}

Physics Department, Faculty of Science, University Putra Malaysia, 43400 UPM Serdang, Selangor, Malaysia; E-Mails: hooimingoo@gmail.com (H.M.O.); wmdaud@science.upm.edu.my (W.M.D.W.-Y.)

* Author to whom correspondence should be addressed; E-Mail: halimah@science.upm.edu.my; Tel.: +603-89466657; Fax: +603-89454454.

Received: 16 February 2012; in revised form: 26 March 2012 / Accepted: 26 March 2012 /

Published: 11 April 2012

\begin{abstract}
A series of binary tellurite based glasses $\left(\mathrm{Bi}_{2} \mathrm{O}_{3}\right)_{x}\left(\mathrm{TeO}_{2}\right)_{100-x}$ was prepared by melt quenching method. The density, molar volume and refractive index increase when bismuth ions $\mathrm{Bi}^{3+}$ increase, this is due to the increased polarization of the ions $\mathrm{Bi}^{3+}$ and the enhanced formation of non-bridging oxygen (NBO). The Fourier transform infrared spectroscopy (FTIR) results show the bonding of the glass sample and the optical band gap, $E_{\text {opt }}$ decreases while the refractive index increases when the ion $\mathrm{Bi}^{3+}$ content increases.
\end{abstract}

Keywords: tellurite glass; optical band gap; optical properties

\section{Introduction}

Tellurite glass is a good material used in lasers and nonlinear applications, photonic applications and communication applications [1]. Tellurite glass is often used because it is stable at room temperature, has good thermal, optical and electric properties [2,3]. This glass has a low photon energy, a high linear and non-linear refractive index, and it also can be used in photorefractive materials, nonlinear devices, up-conversion lasers and optical amplifiers [4-6]. Metal oxides such as $\mathrm{Bi}_{2} \mathrm{O}_{3}, \mathrm{Sb}_{2} \mathrm{O}_{3}$, $\mathrm{MoO}_{3}$ and $\mathrm{Nb}_{2} \mathrm{O}_{5}$ have been added to the tellurite glass system in order to enhance the optical behavior $[7,8]$. Many studies on tertiary tellurite based glass have been done by various authors [9-16]. For example, Tiefeng et al. (2011) [14] studied the optical non linear properties of $\mathrm{TeO}_{2}-\mathrm{Bi}_{2} \mathrm{O}_{3}-\mathrm{BaO}$ glass, and was found that an increase of the ion bismuth content and a decrease of 
ion barium content increased the non linear properties of the glass as bismuth dissolved in the tellurite glass matrix.

Bismuth (iii) oxide is used in optical fiber and ceramic materials because it can provide a high refractive index and low temperatures [17]. In addition, it is also used in the electronic field due to it having a high valence cation of low field strength and high polarizability [18]. In this paper, the optical and physical properties were determined with different ion bismuth contents of tellurite base glass. Optical properties such as the optical band gap and refractive index of binary bismuth tellurite glass were studied. In addition, the density and molar volume of a tellurite glass system was determined.

\section{Results and Discussion}

\section{1. $X R D$}

The XRD results (Figure 1) show that the bismuth tellurite glass is in an amorphous phase. Sample TB 5 (refer to Table 1) is a transparent glass of a dark orange color, while TB 8, TB10, TB12 and TB15 are transparent glasses of a yellow color.

Table 1. Molar mass, density and molar volume of the $\left(\mathrm{Bi}_{2} \mathrm{O}_{3}\right)_{x}\left(\mathrm{TeO}_{2}\right)_{100-x}$ glass system.

\begin{tabular}{lcccc}
\hline Samples & $\boldsymbol{x}(\mathbf{m o l} \%)$ & Molar mass $\mathbf{( g / m o l})$ & Density $\left(\mathbf{g} / \mathbf{c m}^{\mathbf{3}}\right)$ & Molar Volume $\left(\mathbf{c m}^{\mathbf{3}} \mathbf{m o l}\right)$ \\
\hline TB5 & 5 & 174.92 & 5.43 & 32.22 \\
TB8 & 8 & 184.11 & 5.69 & 32.35 \\
TB10 & 10 & 190.23 & 5.85 & 32.49 \\
TB12 & 12 & 196.36 & 6.03 & 32.56 \\
TB15 & 15 & 205.55 & 6.26 & 32.86 \\
\hline
\end{tabular}

Figure 1. X-ray diffraction (XRD) analysis of the $\left(\mathrm{Bi}_{2} \mathrm{O}_{3}\right)_{x}\left(\mathrm{TeO}_{2}\right)_{100-x}$ glass system.

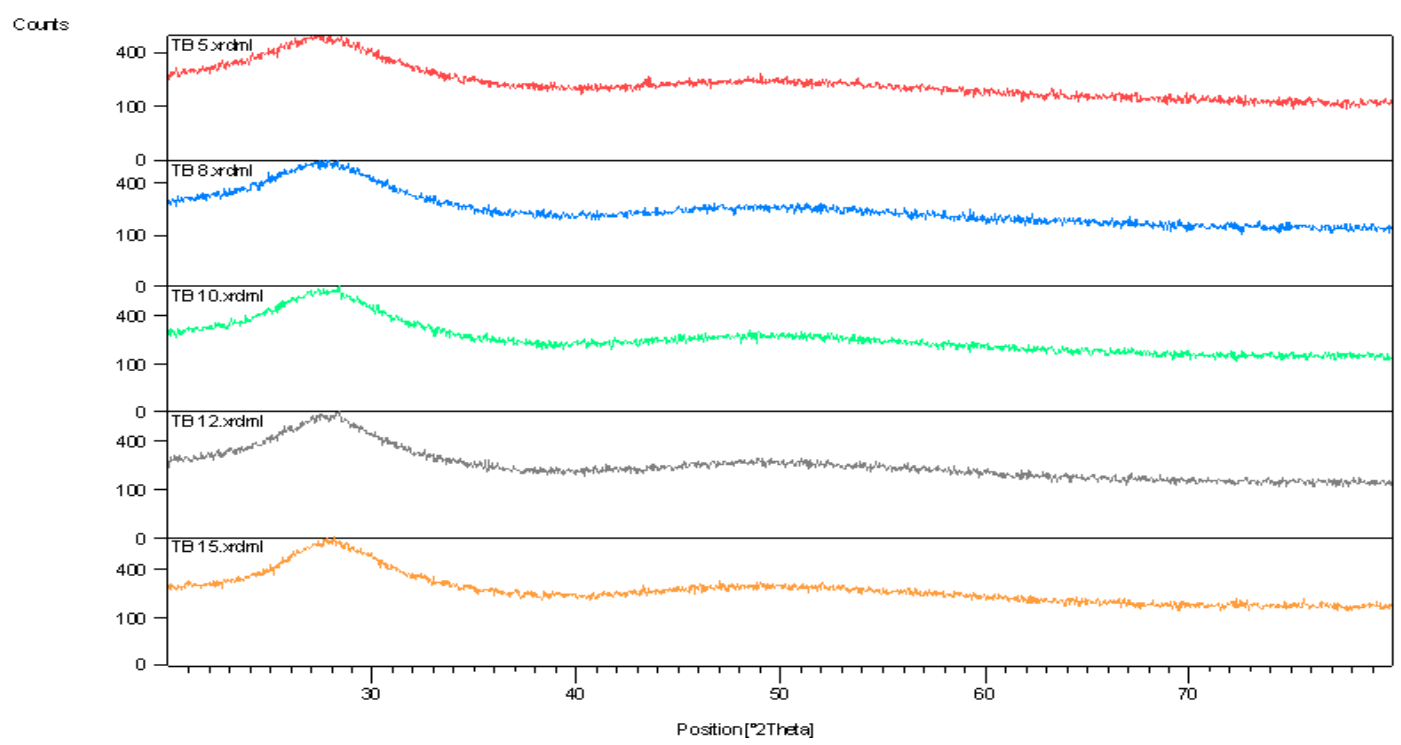

\subsection{Density and Molar Volume}

The density of the glass samples increases as the bismuth content increases. The densities of the bismuth tellurite glasses range from $5.43 \mathrm{~g} / \mathrm{cm}^{3}$ to $6.26 \mathrm{~g} / \mathrm{cm}^{3}$, as shown in Table 1 . Figure 2 shows the 
molar volume and the density increase proportional to the bismuth content. The molar mass of the bismuth (iii) oxide $(465.96 \mathrm{~g} / \mathrm{mol})$ is heavier than the molar mass of tellurite oxide $(159.60 \mathrm{~g} / \mathrm{mol})$ and hence, the glass matrix becomes more dense when $\mathrm{Bi}^{3+}$ ions are added into the glass network [19]. In addition, the increase in molar volume is due to the atomic radius of $\mathrm{Bi}^{3+}(1.70 \AA)$ which is higher than that of tellurite (1.60 $\AA$ ). Usually, the density of the glass changes in the inverse direction of the molar volume, but in this study, the density and molar volume increase with the bismuth contents, this anomaly was also found by Saddek et al. (2007) and Halimah et al. (2010) [20,21].

Figure 2. Density and molar volume with mole fraction of bismuth (iii) oxide of the $\left(\mathrm{Bi}_{2} \mathrm{O}_{3}\right)_{x}\left(\mathrm{TeO}_{2}\right)_{100-x}$ glass system.

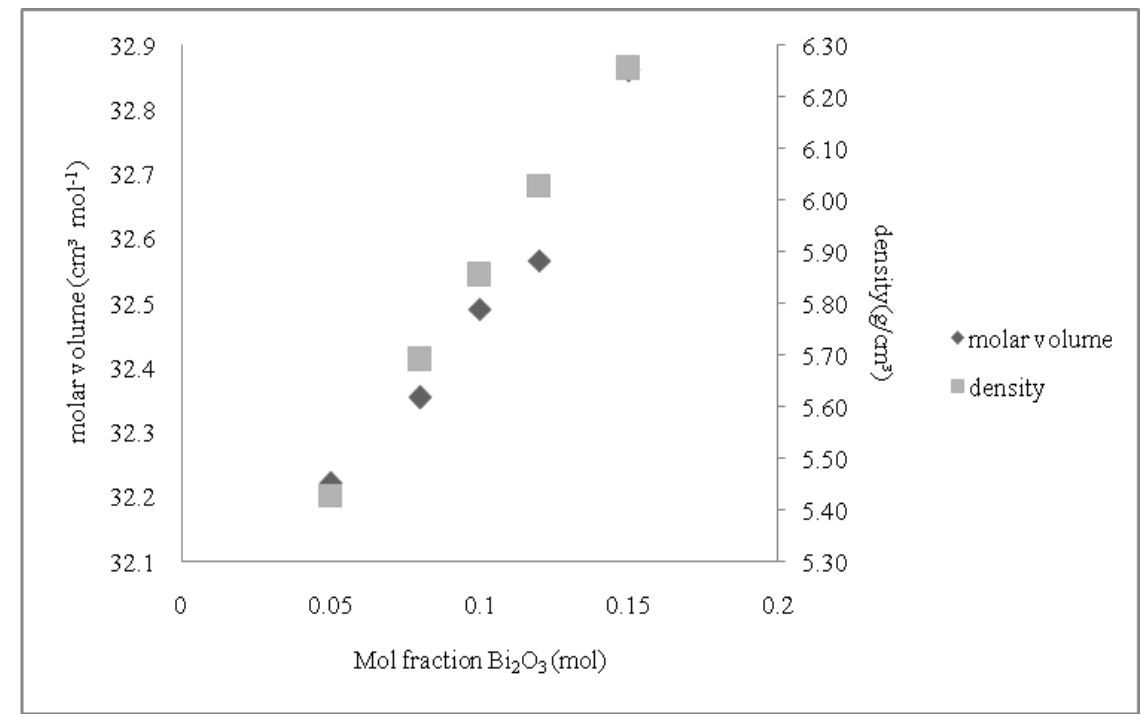

\subsection{FTIR Results}

As shown in Figure 3, the FTIR analysis shows that the $\mathrm{TeO}_{2}$ is the framework former while $\mathrm{Bi}_{2} \mathrm{O}_{3}$ is the glass modifier in the bismuth tellurite glasses system. Table 2 shows the ranges of the wave numbers for difference mode. The wave number for the bismuth tellurite glass system is slightly shifted to the lower wave numbers when the ion $\mathrm{Bi}^{3+}$ concentration is increased. There is a diffuse band in the range of $500-600 \mathrm{~cm}^{-1}$, due to the disordered structure; this is considered as the vibration modes of both the $\mathrm{TeO}_{3}$ and the $\mathrm{TeO}_{4}$ entities [22]. The vibration modes of the bonds for $\mathrm{TeO}_{3+1}$ polyhedra is also found at bands around $580 \mathrm{~cm}^{-1}$ where the $\mathrm{TeO}_{3+1}$ polyhedra consists of an intermediate coordination of the tellurium atoms between 3 and 4 [17], this is found in the all glass samples. On the other hand, the shoulder form in the range of $800-900 \mathrm{~cm}^{-1}$ in TB8, TB10, TB12 and $\mathrm{TB} 15$ is due to the symmetrical stretching vibration of the $\mathrm{Bi}-\mathrm{O}$ bonds in $\mathrm{BiO}_{3}$ units. This band is not observed in the TB5 because the $\mathrm{Bi}^{3+}$ ions present in this glass sample contain non-bridging oxygen in the form of $[\mathrm{BiO}]^{-}$defects. As the ion $\mathrm{Bi}^{3+}$ content increases, bismuth oxide as the network modifier ion modifies the glass structure and enhances the breaking of axial Te-O-Te linkages in the trigonal bipyramids $\left[\mathrm{TeO}_{4}\right]$ (tbp) and creates the formation of trigonal pyramid $\left[\mathrm{TeO}_{3}\right]$ (tp) units and non-bridging oxygen. 
Table 2. The ranges of the wave numbers for difference mode.

\begin{tabular}{cc}
\hline Wavenumber $\left(\mathbf{c m}^{-\mathbf{1}}\right)$ & Mode \\
\hline $400-600$ & $\mathrm{Bi}-\mathrm{O}-\mathrm{Bi}+\mathrm{Bi}-\mathrm{O}$ in $\mathrm{BiO}_{6}$ octahedral $[23]$ \\
$650-660$ & $\mathrm{Te}-\mathrm{Oax}$ in $\left[\mathrm{TeO}_{4}\right][24,25]$ \\
775 & $\mathrm{Te}-\mathrm{Oeq}$ in $\left[\mathrm{TeO}_{4}\right][26,27]$ \\
633,695 & (shoulders) $\mathrm{Te}_{-}-\mathrm{O}^{-}[10]$ \\
$600-610$ & $\mathrm{Bi}-\mathrm{O}^{-}$stretch in $\mathrm{BiO}_{6}$ units $[28]$ \\
$860-865$ & $\mathrm{Bi}-\mathrm{O}$ vibration in distorted $\mathrm{BiO}_{6}$ units $[11]$ \\
\hline
\end{tabular}

Figure 3. FTIR analysis of $\left(\mathrm{Bi}_{2} \mathrm{O}_{3}\right)_{x}\left(\mathrm{TeO}_{2}\right)_{100-x}$ glass system.

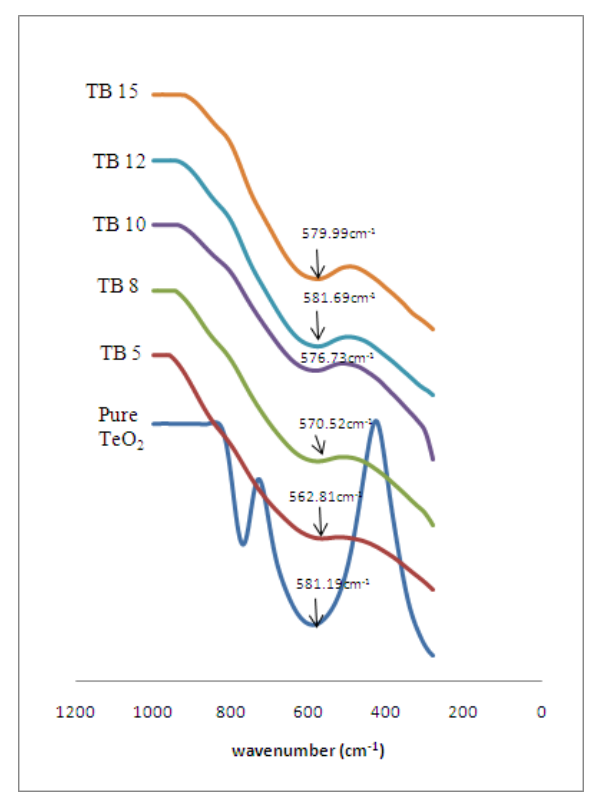

\subsection{Refractive Index and Optical Absorption}

When the bismuth content increases, the refractive index measured at the wavelength of $632.8 \mathrm{~nm}$ increases from 1.97 to 2.12 . The refractive index increase is due to the ion $\mathrm{Bi}^{3+}$ which has a high polarity that can break the bridging oxygen [BO] to non-bridging oxygen [NBO]. In addition, non-bridging oxygen also has an effect on the refractive index, because of the polarity of non-bridging oxygen (NBO) is higher than that of bridging oxygen [29]. As a result, $\mathrm{Bi}_{2} \mathrm{O}_{3}$ will affect the $\mathrm{TeO}_{2}$ based glasses and forms highly polarized non-bridging oxygen ions at the terminals of $\mathrm{Te}-\mathrm{O}$ bonds.

Table 3. Direct optical bandgap, indirect optical bandgap and Urbach energy of $\left(\mathrm{Bi}_{2} \mathrm{O}_{3}\right)_{x}\left(\mathrm{TeO}_{2}\right)_{100-x}$ glass system.

\begin{tabular}{ccccc}
\hline Sample glass & $\begin{array}{c}\text { Indirect bandgap, } \\
\boldsymbol{E}_{\text {opt }}(\mathbf{e V})\end{array}$ & $\begin{array}{c}\text { Direct } \\
\text { bandgap }(\mathbf{e V})\end{array}$ & $\begin{array}{c}\text { Urbach energy, } \\
\boldsymbol{E}_{\mathbf{g}}(\mathbf{e V})\end{array}$ & $\begin{array}{c}\text { Refractive index in } \\
\text { wavelength } \mathbf{6 3 2 . 8} \mathbf{~ n m , ~} \boldsymbol{n}\end{array}$ \\
\hline TB 5 & 2.40 & 3.02 & 0.44 & 1.97 \\
TB 8 & 2.77 & 3.10 & 0.22 & 1.99 \\
TB 10 & 2.75 & 3.08 & 0.23 & 2.02 \\
TB 12 & 2.70 & 3.04 & 0.24 & 2.07 \\
TB 15 & 2.60 & 3.00 & 0.25 & 2.12 \\
\hline
\end{tabular}


The optical absorption spectra were taken in the ranges of 350 to $500 \mathrm{~nm}$. For the optical band gap in this bismuth tellurite glass system, the optical band gap energy, $E_{\text {opt }}$ decreases when the ion bismuth content increases as shown in Table 3.

The optical band gap energy is determined by using the following equation [30]

$$
\alpha h v=A\left(h v-E_{\mathrm{opt}}\right)^{n}
$$

where $\alpha$ is the absorption coefficient, $h v$ is the incident photon energy, $A$ is a constant and $E_{\text {opt }}$ is the optical band gap. Values of $n$ are 2 and 1/2 for direct and indirect transitions, respectively. The indirect band gap as a function of photon energy for $\left(\mathrm{Bi}_{2} \mathrm{O}_{3}\right)_{x}\left(\mathrm{TeO}_{2}\right)_{100-x}$ glass system is plotted and shown in Figure 4.

According to Sayed (2005), amorphous or glassy materials consist of a band tailing in the forbidden energy band gap. The band tailing might arise from random fluctuations of the internal disorder in the amorphous materials. So it can be estimated using the Urbach equation shown as follows [31]

$$
\alpha(v)=B \exp \left(h v / \Delta E_{g}\right)
$$

where $B$ is a constant and $\Delta E$ is the width of the band tail of the electron states. From Figure 5, Urbach energy, $E_{\mathrm{g}}$ is determined from the slope of plot $\ln (\alpha)$ versus $h v$.

The range of the indirect optical band gap decreases from $2.40 \mathrm{eV}$ to $2.60 \mathrm{eV}$ and $3.00 \mathrm{eV}$ to $3.02 \mathrm{eV}$ for the direct band gap as the concentration of ion $\mathrm{Bi}^{3+}$ increases in the bismuth tellurite glass system. However, sample TB5 has a low bismuth content and a low energy band gap because of the formation of $\mathrm{TeO}_{2}$ linkages in $\mathrm{Te}-\mathrm{O}$ where bridging oxygen is more frequent than non-bridging oxygen. Shifting of the absorption band to a lower energy can be related to the formation of non-bridging oxygen (NBO) which binds exited electrons of non-bridging oxygen less tightly than bridging oxygen [10], and this cause the glass network to become less rigid (Rajendan, 2003) [27]. Another possibility is due to the high polarizability of the $\mathrm{Bi}^{3+}$ ions which can be attributed to the empty d orbitals of the corresponding cations and also their high coordination number towards oxide ions. The coordination number of $\mathrm{TeO}_{2}$ changes from 4 to 3 while the coordination number of $\mathrm{Bi}_{2} \mathrm{O}_{3}$ changes from 3 to 6 , which then forms a $\mathrm{BiO}_{6}$ octaherdal structural unit with the addition of $\mathrm{Bi}_{2} \mathrm{O}_{3}$ into the glass system. According to Yanfei (2008) [16], less tight oxygen anions were allowed when the amount of non-bridging oxygen increased, This was because of an increase in Lewis basicity of oxide ions, which form stronger covalent Te-O bonds in $\mathrm{TeO}_{3}$ units, and so allow less tight oxygen anions in the glass network. Hence the more the $\mathrm{Bi}_{2} \mathrm{O}_{3}$ content increases, the fewer tightly bound oxygen anions (valence electrons) are found and the greater the decrease of the optical band gap energies. 
Figure 4. Plot of $(\alpha \mathrm{hv})^{1 / 2}$ versus $h v$ for indirect band gap of $\left(\mathrm{Bi}_{2} \mathrm{O}_{3}\right)_{x}\left(\mathrm{TeO}_{2}\right)_{100-x}$ glass system.

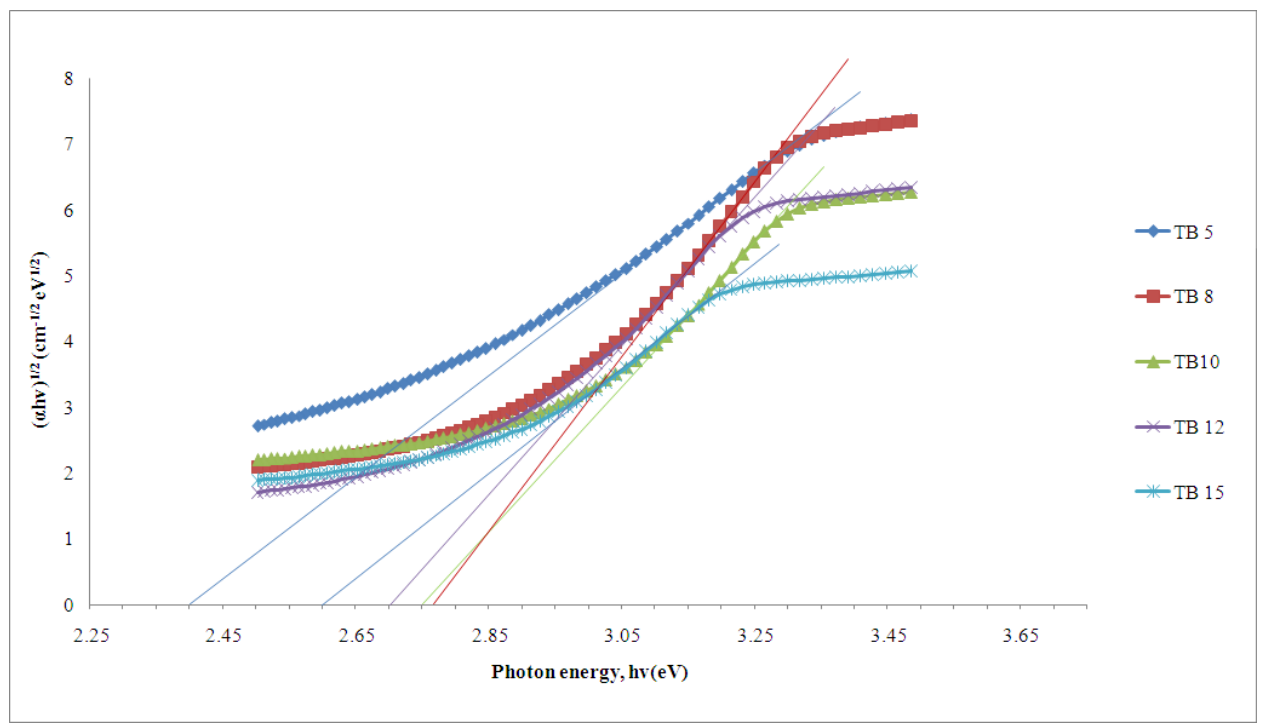

Figure 5. Plot of $\ln (\alpha)$ versus $h v$ for Urbach energy of $\left(\mathrm{Bi}_{2} \mathrm{O}_{3}\right)_{x}\left(\mathrm{TeO}_{2}\right)_{100-x}$ glass system.

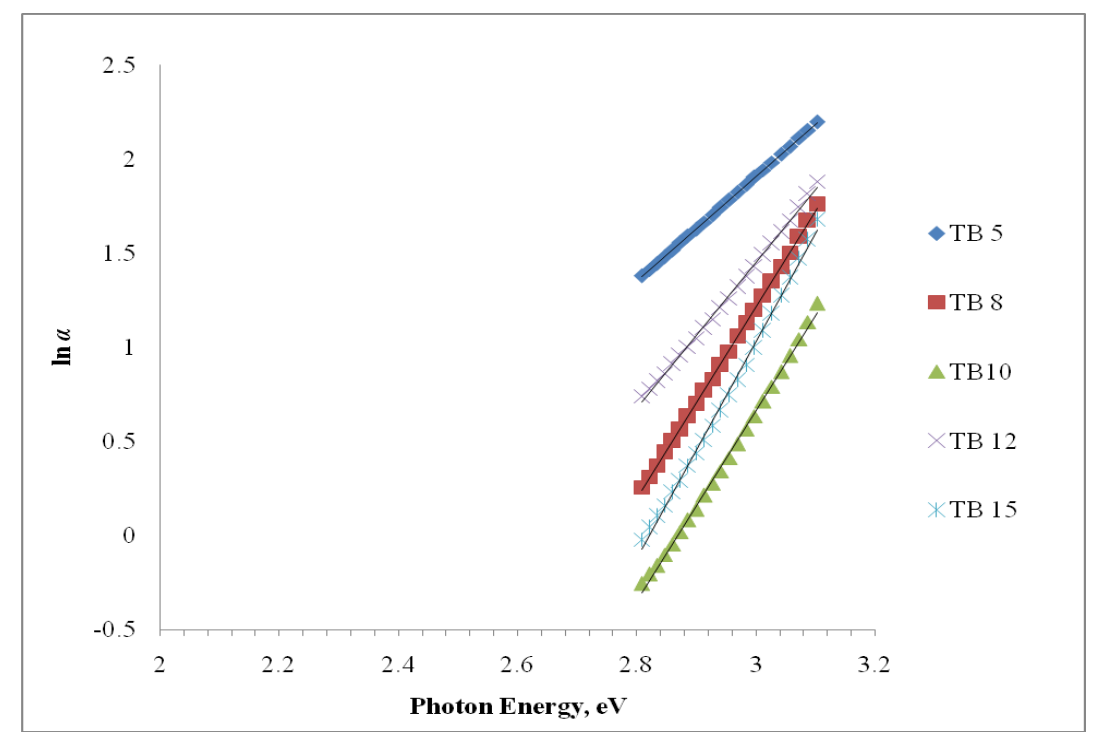

The optical band gap energy is opposite to the Urbach energy, which can be attributed to the formation of non-bridging oxygen (Figure 6). The optical band gap energy and Urbach energy values for glass systems are found to lie between $3.10-3.00 \mathrm{eV}$ and $0.25-0.44 \mathrm{eV}$, respectively. Rajendran (2003) [27] reported that the addition of $\mathrm{Bi}_{2} \mathrm{O}_{3}$ glass modifier would make the glass network more loosely packed (breaking the $\mathrm{O}-\mathrm{Te}-\mathrm{O}$ chains to form $\mathrm{TeO}_{3}$ units and non-bridging oxygen) and therefore produce unstable glass. When the concentration of ion $\mathrm{Bi}^{3+}$ is increased, the appearance of $\mathrm{TeO}_{3}$ units and non-bridging oxygen in the glass networks increases. As the concentration of the ion modifier $\mathrm{Bi}^{3+}$ increases, non-bridging oxygen and $\mathrm{TeO}_{3}$ units in the glass structure increase and as a result, the Urbach energy for this glass system also increases. 
Figure 6. The optical band gap energy, $E_{\text {opt }}$ and Urbach energy, $E_{\mathrm{g}}$ of $\left(\mathrm{Bi}_{2} \mathrm{O}_{3}\right)_{x}\left(\mathrm{TeO}_{2}\right)_{100-x}$ glass system.

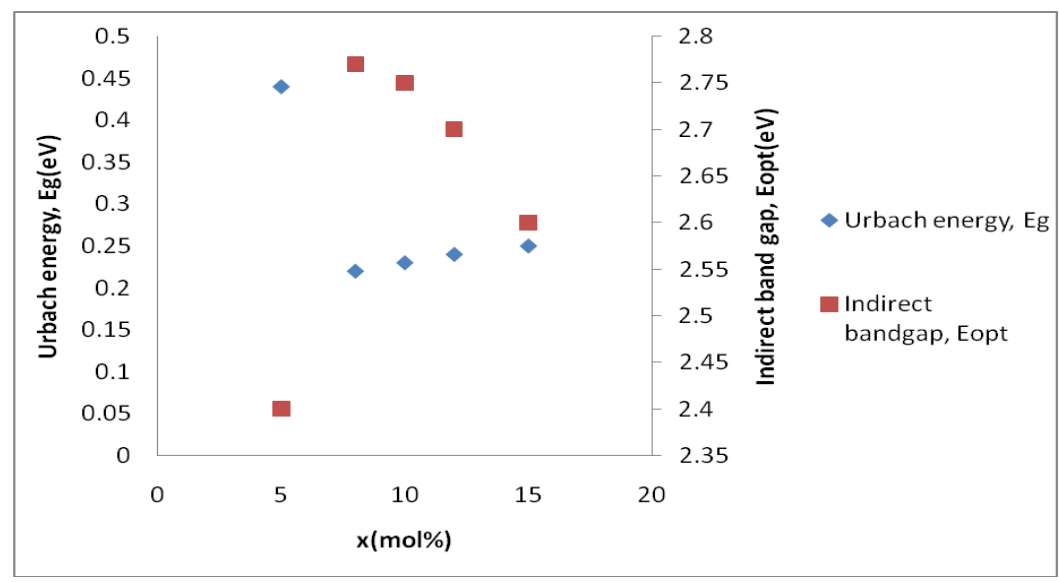

\section{Experimental}

The raw materials of tellurium dioxide, $\mathrm{TeO}_{2}$ (Aldrich 99.5\%), and bismuth (iii) oxide $\mathrm{Bi}_{2} \mathrm{O}_{3}$ (Aldrich 99.0\%) were used to synthesize the glass sample. The glass sample was prepared by using a melt quenching method [32,33]. The bismuth (iii) oxide, $x=5,8,10,12,15$ in mol\% was added into the tellurite oxide and was weighed using a digital weighing machine with an accuracy of $\pm 0.01 \mathrm{~g}$ and then mixed together by using a mortar and pestle. The mixture was poured into an alumina crucible and put into an electric furnace set at $100{ }^{\circ} \mathrm{C}$ for a period of $30 \mathrm{~min}$. The alumina crucible was used because it can withstand high temperatures and does not react with the raw materials during the melting process as opposed to porcelain crucibles. The temperature was then increased by $10{ }^{\circ} \mathrm{C} / \mathrm{min}$ until $900{ }^{\circ} \mathrm{C}$ and the then maintained for $2 \mathrm{~h}$. When the melting process was completed, the molten liquid was cast into a stainless steel cylindrical shape mould which had been preheated at $400{ }^{\circ} \mathrm{C}$ for $30 \mathrm{~min}$. The sample was annealed at $400{ }^{\circ} \mathrm{C}$ in a second furnace for $1 \mathrm{~h}$, then the furnace was turned off. The glass sample was cut at a thickness of about $2 \mathrm{~mm}$ for the required measurements [33].

The density of the glass samples was measured using the Archimedes principle, and distilled water was used as the immersion liquid. The optical properties such as refractive indices $(n)$ were determined by using EL X-02C high precision ellipsometer. The structure of the bismuth tellurite glass was investigated using X-ray diffraction (XRD) and Fourier transform infrared spectroscopy (FTIR). The optical absorption of the bismuth tellurite glass was measured using UV visible spectroscopy and powder $\mathrm{BaSO}_{4}$ was used as the reference for the UV visible spectroscopy. The wavelength was set from 2600 $\mathrm{nm}$ to $220 \mathrm{~nm}$, and the internal spacing was $0.2 \mathrm{~nm}$, using a medium scan speed for glass samples.

\section{Conclusions}

The density and molar volume of the glass sample increase due to the fact that the atomic mass of bismuth ions is higher than that of tellurite ions, and that the atomic radius of bismuth is also greater than that of tellurite ions. Additionally, the refractive index increases due to the increase of polarity of the $\mathrm{Bi}^{3+}$ ion content in tellurite based glasses. In addition, based on the FTIR results, the $\mathrm{TeO}_{2}$ is the glass former while $\mathrm{Bi}_{2} \mathrm{O}_{3}$ is the glass modifier in bismuth tellurite glass systems, and the wave number 
shifts to a low frequency when the bismuth content increases. The optical band gap shifts to a low energy while the Urbach energy shifts to high energy when non-bridging oxygen (NBO) increases as bismuth content increases.

\section{Acknowledgments}

The authors appreciate the financial support for the work from the Ministry of Higher Education of Malaysia through RUGS (9199837).

\section{References}

1. Vijaya Prakash, G.; Narayana Rao, D.; Bhatnagar, A.K. Linear optical properties of niobium based tellurite glasses. Solid State Commun. 2001, 119, 39-44.

2. Mohamed, N.B.; Yahya, A.K.; Deni, M.S.M.; Mohamed, S.N.; Halimah, M.K.; Sidek, H.A.A. Effects of concurrent $\mathrm{TeO}_{2}$ reduction and $\mathrm{ZnO}$ addition on elastic and structural properties of $(90-x) \mathrm{TeO}_{2}-10 \mathrm{Nb}_{2} \mathrm{O}_{5}-(x) \mathrm{ZnO}$ glass. J. Non-Cryst. Solids 2010, 356, 1626-1630.

3. Foldvari, I.; Peter, A. Basic spectroscopic properties of bismuth tellurium oxide, $\mathrm{Bi}_{2} \mathrm{TeO}_{5}$. J. Mater. Sci. 1992, 27, 750-754.

4. Udovic, M.; Valant, M.; Suvorov, D. Phase formation and dielectric characterization of the $\mathrm{Bi}_{2} \mathrm{O}_{3}-\mathrm{TeO}_{2}$ system prepared in an oxygen atmosphere. J. Am. Ceram. Soc. 2004, 87, 591-597.

5. Ozdanova, J.; Ticha, H.; Tichy, L. Optical band gap and Raman spectra in some $\left(\mathrm{Bi}_{2} \mathrm{O}_{3}\right)_{x}\left(\mathrm{WO}_{3}\right)_{y}\left(\mathrm{TeO}_{2}\right)_{100-x-y}$ and $(\mathrm{PbO})_{x}\left(\mathrm{WO}_{3}\right)_{y}\left(\mathrm{TeO}_{2}\right)_{100-x-y}$ glasses. J. Non-Cryst. Solids 2009, $355,2318-2322$.

6. Boyer, J.C.; Vetrone, F.; Capobianco, J.A. Optical transitions and upconversion properties of $\mathrm{Ho}_{3+}$ doped $\mathrm{ZnO}-\mathrm{TeO}_{2}$ glass. J. Appl. Phys. 2003, 93, 9460-9465.

7. Mori, H.; Kitami, T.; Sakata, H. Electrical conductivity of $\mathrm{W}_{2} \mathrm{O}_{5}-\mathrm{Sb}_{2} \mathrm{O}_{3}-\mathrm{TeO}_{2}$ glasses. J. Non-Cryst. Solids 1994, 168, 157-166.

8. Szu, S.P.; Chang, F.-S. Impedance study of $\mathrm{V}_{2} \mathrm{O}_{5}-\mathrm{TeO}_{2}-\mathrm{BaO}$ glasses. Solid State Ion. 2005, 176, 2695-2699.

9. Ayuni, J.N.; Halimah, M.K.; Talib, Z.A.; Sidek, H.A.A.; Daud, W.M.; Zaidan, A.W.; Khamirul, A.M. Optical properties of ternary $\mathrm{TeO}_{2}-\mathrm{B}_{2} \mathrm{O}_{3}-\mathrm{ZnO}$ glass system. Mater. Sci. Eng. 2011, 17, doi:10.1088/1757-899X/17/1/012027.

10. Mohamed, N.B.; Yahya, A.K.; Deni, M.S.M.; Mohamed, S.N.; Halimah, M.K.; Sidek, H.A.A. Effects of concurrent $\mathrm{TeO}_{2}$ reduction and $\mathrm{ZnO}$ addition on elastic and structural Properties of $(90-\mathrm{x}) \mathrm{TeO}_{2}-10 \mathrm{Nb}_{2} \mathrm{O}_{5}-(\mathrm{x}) \mathrm{ZnO}$ glass. J. Non-Cryst. Solids 2010, 356, 1626-1630.

11. Boris, L.S.; Petrov, T.; Yoneda, H.; Rositsa, T.; Boriana, M. Synthesis and nonlinear optical properties of $\mathrm{TeO}_{2}-\mathrm{Bi}_{2} \mathrm{O}_{3}-\mathrm{GeO}_{2}$ glasses. Scr. Mater. 2009, 61, 493-496.

12. Durga, D.K.; Veeraiah, N. Dielectric dispersion in $\mathrm{ZnF}_{2}-\mathrm{Bi}_{2} \mathrm{O}_{3}-\mathrm{TeO}_{2}$ glass system. J. Mater. Sci. 2001, 36, 5625-5632.

13. Yousef, E.S.S. Characterization of oxyfluoride tellurite glasses through thermal, optical and ultrasonic measurements. J. Phys. D Appl. Phys. 2005, 38, 3970-3975.

14. Xu, T.; Chen, F.; Dai, S.; Shen, X.; Wang, X.; Nie, Q.; Liu, C. Glass formation and third-order optical nonlinear properties within $\mathrm{TeO}_{2}-\mathrm{Bi}_{2} \mathrm{O}_{3}-\mathrm{BaO}$ pseudo-ternary system. J. Non-Cryst. Solids 2011, 357, 2219-2222. 
15. Senthil Murugan, G.; Fargin, E.; Rodriguez, V.; Adamietz, F.; Couzi, M.; Buffeteau, T.; Le Coustumer, P. Temperature-assisted electrical poling of $\mathrm{TeO}_{2}-\mathrm{Bi}_{2} \mathrm{O}_{3}-\mathrm{ZnO}$ glasses for non-linear optical application. J. Non-Cryst. Solids 2004, 344, 158-166.

16. Wang, Y.; Dai, S.; Chen, F.; Xu, T.; Nie, Q. Physical properties and optical band gap of new tellurite glasses within the $\mathrm{TeO}_{2}-\mathrm{Nb}_{2} \mathrm{O}_{5}-\mathrm{Bi}_{2} \mathrm{O}_{3}$ system. Mater. Chem. Phys. 2009, 113, 407-411.

17. El-Mallawany, R.A.H. Tellurite Glasses Handbook; CRC Press Inc.: Boca Raton, FL, USA, 2002.

18. El-Mallawanny, R.; Dirar Abdalla, M.; Abbas Ahmed, I. New tellurite glass: Optical properties. Mater. Chem. Phys. 2008, 109, 291-296.

19. Sidek, H.A.A.; Rosmawati, S.; Talib, Z.A.; Halimah, M.K.; Daud, W.M. Synthesis and optical properties of $\mathrm{ZnO}-\mathrm{TeO}_{2}$ glass system. Am. J. Appl. Sci. 2009, 6, 1489-1494.

20. Saddeek, Y.B.; Yasser, B.; Afifi, H.A.; Abd El-Aal, N.S. Interpretation of mechanical properties and structure of $\mathrm{TeO}_{2}-\mathrm{Li}_{2} \mathrm{O}-\mathrm{B}_{2} \mathrm{O}_{3}$ glasses. Phys. B 2007, 398, 1-7.

21. Halimah, M.K.; Sidek, H.A.A.; Daud, W.M.; Zainal, A.S.; Mansor, H.; Khamirul, A.M. Physical properties of binary tellurite glass system. Solid State Sci. Tech. 2010, 18, 364-370.

22. Munoz-Matin, D.; Villegas, M.A.; Gonzalo, J.; Fernandez-Navarro, J.M. Characterisation of glasses in the $\mathrm{TeO}_{2}-\mathrm{WO}_{3}-\mathrm{PbO}$ system. J. Eur. Ceram. Soc. 2009, 29, 2903-2913.

23. Doweidar, H.; Saddeek, Y.B. FTIR and Ultrasonic investigations on modified bismuth borate glasses. J. Non-Cryst. Solids 2009, 355, 348-354.

24. Wanga, G.; Zhanga, J.; Daia, S.; Wena, L.; Yanga, J.; Jianga, Z. Structural investigation on $\mathrm{TeO}_{2}-\mathrm{BiCl}_{3}$ glassy system. J. Mol. Struct. 2005, 750, 1-6.

25. Ok, K.M.; Bhuvanesh, N.S.P.; Shiv Halasyamani, P. $\mathrm{Bi}_{2} \mathrm{TeO}_{5}$ : Synthesis, structure, and powder second harmonic generation properties. Inorg. Chem. 2001, 40, 1978-1980.

26. Pascuta, P.; Culea, E. FTIR spectroscopic study of some bismuth germinate glasses containing gadolinium ions. Mater. Lett. 2008, 62, 4127-4129.

27. Rajendran, V.; Palanivelu, N.; Chaudhuri, B.K.; Goswami, K. Characterisation of semiconducting $\mathrm{V}_{2} \mathrm{O}_{5}-\mathrm{Bi}_{2} \mathrm{O}_{3}-\mathrm{TeO}_{2}$ glasses through ultrasonic measurements. J. Non-Cryst. Solids 2003, 320, 195-209.

28. Halimah, M.K.; Daud, W.M.; Sidek, H.A.A.; Zaidan, A.W.; Zainal, A.S. Optical properties of ternary tellurite glasses. Mater. Sci. Pol. 2010, 28, 173-180.

29. Chen, Y.; Nie, Q.; Xu, T.; Dai, S.; Wang, X.; Shen, X. A study of nonlinear optical properties in $\mathrm{Bi}_{2} \mathrm{O}_{3}-\mathrm{WO}_{3}-\mathrm{TeO}_{2}$ glasses. J. Non-Cryst. Solids 2008, 354, 3468-3472.

30. Tauc, J. Amorphous and Liqiud Semiconductors; Plenum: New York, NY, USA, 1974.

31. Urbach, F. The long-wavelenght edge of photographic sensitivity and of the electronic absorption of solids. Phys Rev. 1953, 92, doi:10.1103/PhysRev.92.1324.

32. Doweidar, H.; Yasser, B.S. FTIR and ultrasonic investigations on modified bismuth borate glasses. J. Non-Cryst. Solids 2009, 355, 348-354.

33. Sidek, H.A.A.; Rosmawati, S.; Talib, Z.A.; Halimah, M.K.; Halim, S.A. Effect of zinc on the elastic behaviour of $\left(\mathrm{TeO}_{2}\right)_{90}\left(\mathrm{AlF}_{3}\right)_{10-x}(\mathrm{ZnO})_{x}$ glass system. Int. J. Basic Appl. Sci. 2010, 9, 401-407.

(C) 2012 by the authors; licensee MDPI, Basel, Switzerland. This article is an open access article distributed under the terms and conditions of the Creative Commons Attribution license (http://creativecommons.org/licenses/by/3.0/). 